Research Article

\title{
An Approach to Estimate SCC Growing Rate in Slow Strain Rate Tensile Test Based on EPFEM
}

\author{
Shuai Wang $\mathbb{D}^{1,2}$ He Xue $\mathbb{D}^{1},{ }^{1}$ Yinghao Cui, ${ }^{1}$ Fuqiang Yang $\mathbb{D}^{3},{ }^{3}$ and Rui Guo $\mathbb{D}^{1}$ \\ ${ }^{1}$ School of Mechanical Engineering, Xi'an University of Science and Technology, Xi'an 710054, China \\ ${ }^{2}$ College of Engineering, Design and Physical Sciences, Brunel University, London UB8 3PH, UK \\ ${ }^{3}$ School of Science, Xi'an University of Science and Technology, Xi'an 710054, China \\ Correspondence should be addressed to He Xue; xue_he@hotmail.com
}

Received 12 April 2019; Accepted 14 May 2019; Published 11 June 2019

Guest Editor: Dariusz Rozumek

Copyright ( $\odot 2019$ Shuai Wang et al. This is an open access article distributed under the Creative Commons Attribution License, which permits unrestricted use, distribution, and reproduction in any medium, provided the original work is properly cited.

\begin{abstract}
The slow strain rate tensile test (SSRT) is a common means to investigate stress corrosion cracking (SCC) in key engineering structural materials of light-water reactors, and it is an important task to real-time monitor the crack growing length and rate of the specimen during the test. Because the specimen is placed in an autoclave with high-pressure and high-temperature water environment-simulated light-water reactor, the current potential drop method, which includes current potential drop (DCPD) and alternating current potential drop (ACPD), is the main means to real-time monitor crack growth rate in the SCC test. As a supplementary means to obtain the crack growth rate during the test, the SSRT process of nickel-based Alloy 600 CT specimens is investigated by using the elastic-plastic finite element method (EPFEM) in this paper. Based on the consideration that both the elastic-plastic deformation and crack length of the specimen would affect the relationship between the load and the displacement of the loading point during the SSRT test, the relationship between the loading point displacement caused by crack propagation $\Delta L_{\mathrm{c}}$ and plastic deformation $\Delta L_{\mathrm{p}}$ is separated by EPFEM. Then, the SCC crack growth rate and the real-time crack length are obtained. This proposed approach could be used to improve the test results in the SSRT test.
\end{abstract}

\section{Introduction}

To improve the corrosion resistance of nuclear power equipment, austenitic stainless steel and nickel-based alloys are widely used as the structural materials in the primary circuit of pressurized water reactors (PWRs). Both austenitic stainless steel and nickel-based alloys, however, were found to be susceptible to stress corrosion cracking (SCC) by both laboratory experiment and field experience [1-6]. The SCC is typically associated with the combined effect of residual stress and working stress in a high-temperature water environment; such cracking can affect the reliability, integrity, and economy of PWRs and may become a potential service life-limiting issue [7].

The method for quantitative monitoring of the SCC propagation behaviour of austenitic stainless steel in the high-temperature water environment has been investigated for many years. Hwang et al. have studied the acoustic emission (AE) characteristics of SCC on 304 austenitic stainless steel and conclude that during the SCC development process, specific $\mathrm{AE}$ waveforms were generated, which can distinguish the SCC stages by heating, saturation, maximum temperature and pressure, and leakage [8]. Kovac et al. have studied the IGSCC propagation of sensitized type AISI 304 stainless steel by using four measuring techniques such as $\mathrm{AE}$, electrochemical noise (EN), digital imaging, elongation measurements, and crack propagation were observed in all measured signals, although AE activity occurred only when the crack was large enough. The propagation was also successfully monitored with digital imaging [9]. Satoh et al. compared the EAC growth rate in hightemperature water with or without irradiation by using quantitatively predicting the theoretical model of SCC combined with the finite element method. The results show that the finite element simulation of crack growth rate agrees with the theoretical calculation results under irradiation 
conditions; however, there are deviations in results under nonirradiation conditions [10]. Shi et al. proposed an artificial neural network algorithm (ANN) for predicting the rate of SCC growth of Alloy 600. The results show that the crack propagation rate prediction results obtained by ANN are consistent with the experimental data [11]. Ritchie et al. used the finite element method and the electrical analogue method to study the relationship between crack length and voltage drop of CT specimens. The results show that the crack length and voltage drop are approximately linear [12]. Zhang et al. used the direct current potential drop (DCPD) to conduct SCC growth tests of cold-worked nuclear-grade 316L austenitic stainless steel containing various dissolved oxygen (DO) contents but no dissolved hydrogen. The results showed that the SCC crack growth rates increase with increasing DO content in the simulated PWR primary water environment [13]. Zhai et al. have investigated the SCC initiation of three mill-annealed Alloy 600 heats in simulated pressurized water reactor primary by using constant load tests equipped with DCPD measurement capabilities. The results showed that the initiation time in the ground samples was slightly delayed, and the SCC initiation times were greatly reduced by a small amount of cold work [14].

The slow strain rate tensile test (SSRT) is an important experimental method to evaluate the stress corrosion sensitivity of materials in the high-temperature water environment. In the SSRT test, the direct current potential drop (DCPD) or the alternating current potential drop (ACPD) method are usually used to the real-time measure the crack growth length $[15,16]$. Since DCPD mainly uses time changes in the potential around the crack tip to estimate the crack propagation, the results are highly susceptible to the experimental environment. An estimated method of realtime crack growing rate during the SSRT test is proposed by using the elastic-plastic finite element method (EPFEM) in this paper. Based on the consideration that both the elasticplastic deformation and crack length of the specimen would affect the relationship between the load and the displacement of the loading point during the SSRT test, the relationship between the loading point displacement caused by crack propagation $\Delta L_{\mathrm{c}}$ and plastic deformation $\Delta L_{\mathrm{p}}$ are separated by EPFEM. Then, the SCC crack growth rate and the real-time crack length are obtained.

\section{SSRT Experiment in High- Temperature Water}

2.1. Materials and Specimen. The type Alloy 600 selected from the safety-end welded joint in pressurized water reactors (PWRs) is used in the SSRT experiment. The chemical compositions of the material are shown in Table $1[17,18]$. Standard $12.7 \mathrm{~mm}$ thickness compact tension (CT) specimen with $5 \%$ side grooves on each side was prepared, which is shown in Figure 1 [19].

2.2. Experiment Procedures. SCC crack growth tests were measured using a slow strain rate stress corrosion testing machine equipped with an autoclave, a high-precision heating controller, a servo loading system, and a direct current drop (DCPD) crack length measurement devices. The precrack length on the CT specimen is $10 \mathrm{~mm}$, and the CT specimen is loaded by a displacement load. The load-line displacement change rate $V=0.005 \mathrm{~mm} / \mathrm{h}$, and the test period is 900 hours. The stress corrosion test procedure for Alloy 600 is shown in Figure 2(a). The CT specimen with precrack is fixed by a pin, and a load $P$ was applied to the specimen in the vertical direction as shown in Figure 2(b); the load-line displacement and the crack growth behaviour during the tests was separated monitored by using the sensor on the SSRT machine and the DCPD device.

\section{Calculation Model}

3.1. Material Model. The true stress-strain curve of Alloy 600 can generally be expressed in Ramberg-Osgood relationship, and the equation is written as

$$
\frac{\varepsilon}{\varepsilon_{0}}=\frac{\sigma}{\sigma_{0}}+\alpha\left(\frac{\sigma}{\sigma_{0}}\right)^{n},
$$

where $\sigma_{0}$ is the yield strength of the material, $\varepsilon_{0}$ is the yield strain of the material, respectively, $\alpha$ is the yield offset coefficient of the material, and $n$ is the strain hardening exponent of the material [20]. The mechanical properties of Alloy 600 are shown in Table 2 [21].

3.2. Geometric Model. To investigate the effect of the SSRT process of nickel-based Alloy 600, simulated SCC numerical tests with CT specimen were performed in this investigation. The numerical simulation process was guided by the American Society for Testing and Materials (ASTM) standards [19]. Since the shape and loading mode of the sample are both symmetrical, a one-half model of the CT sample is used in this simulation to reduce the amount of calculation, and the pre-crack length of the sample is $10 \mathrm{~mm}$.

3.3. Finite Element Mesh. The loading process and the crack growth process were simulated by commercial FEM code ABAQUS, which is expected to represent the crack tip stress and strain conditions in the entire SSRT experimental process [22]. The mesh of the specimen is shown in Figure 3, and the mesh nearby the crack tip region of specimen is significantly refined to obtain a more detail and accurate data at the crack tip, where the $X$-axis is the opposite direction of the crack growth, and $Y$-axis is the normal direction of the crack growth in the coordinate system. The crack length extends from $24 \mathrm{~mm}$ to $27 \mathrm{~mm}$ by using node releasing technique during the simulating process.

\section{Results and Discussions}

4.1. SSRT Experiment Results. After 900 hours of slow strain rate stretching, the crack on the CT specimen was expanded from $24 \mathrm{~mm}$ to $27 \mathrm{~mm}$ by using DCPD, and the crack propagation length was about $3 \mathrm{~mm}$. The relationship between the tensile load $P$ and the load line displacement $\Delta L$ is shown in Figure 4. 
TABLe 1: Chemical composition of Alloy 600 (\%).

\begin{tabular}{lcccccccccc}
\hline $\mathrm{C}$ & $\mathrm{Mn}$ & $\mathrm{Fe}$ & $\mathrm{S}$ & $\mathrm{Si}$ & $\mathrm{Cu}$ & $\mathrm{Cr}$ & $\mathrm{P}$ & $\mathrm{Nb}$ & $\mathrm{Ti}$ & $\mathrm{Ni}$ \\
\hline 0.065 & 0.22 & 9.50 & 0.0021 & 0.12 & 0.1 & 15.57 & 0.007 & $<0.05$ & 0.28 & $\mathrm{Bal}$. \\
\hline
\end{tabular}

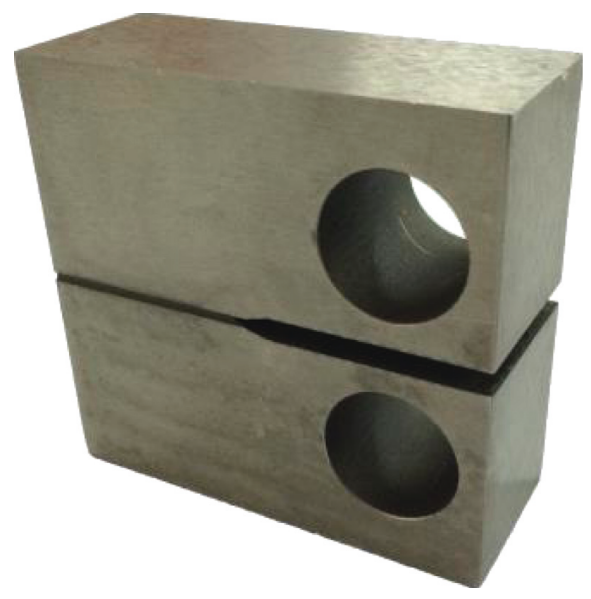

(a)

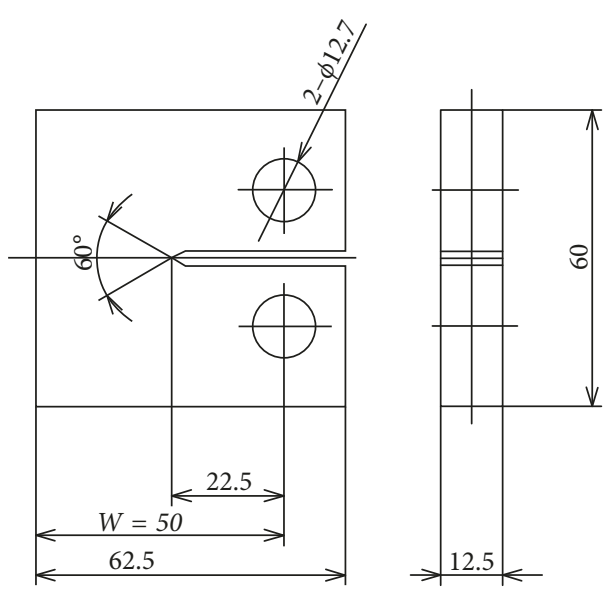

(b)

Figure 1: Compact tension specimen: (a) specimen; (b) geometric dimensioning.

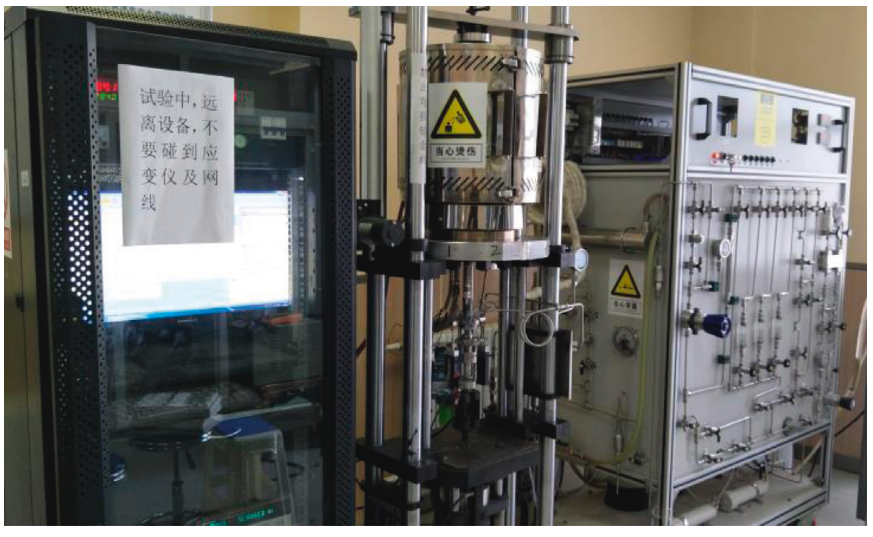

(a)

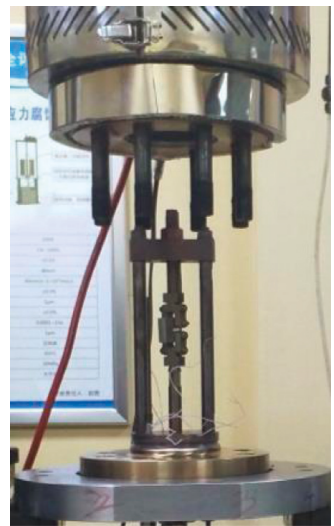

(b)

Figure 2: The SSRT experiment: (a) the test procedure for Alloy 600; (b) the installation position of the CT specimen.

TABle 2: Nickel-based Alloy 600 material mechanical properties at $340^{\circ} \mathrm{C}$.

\begin{tabular}{lccccc}
\hline$\sigma_{0}(\mathrm{MPa})$ & $\mathrm{E}$ & $\alpha$ & $n$ & $E(\mathrm{GPa})$ & $\nu$ \\
\hline 436 & 0.239 & 3.075 & 6.495 & 189.5 & 0.286 \\
\hline
\end{tabular}

4.2. Calculation Result and Analysis. After the numerical simulation is completed, the data of the load line displacement $\Delta L$ and the tensile load $P$ at the load point are extracted, and the relationship between the tensile load $P$ and the load line displacement $\Delta L$ is obtained as shown in Figure 5. Because the whole crack growing length during the test process is about $3 \mathrm{~mm}$, the relation of the tensile load $P$ and the load-line displacement $\Delta L$ are calculated when the crack extends every $0.375 \mathrm{~mm}$, for which the crack length are $0 \mathrm{~mm}, 0.375 \mathrm{~mm}, 0.75 \mathrm{~mm}, 1.125 \mathrm{~mm}, \ldots$, $3 \mathrm{~mm}$, respectively.

The above results are obtained by fixing the deformation path, which fixes the crack propagation length during the slow strain rate test (SSRT), and the relationship between the tensile load $P$ and the load-line displacement $\Delta L$ of the fixed crack length is obtained. By incorporating the FEA results with SSRT result, we could get the intersection of the SSRT test curve and the numerical simulation curve under different crack lengths, thus the load-line displacement $\Delta L_{\mathrm{c}}$ caused by the change in crack length is separated from the total line displacement obtained from the SSRT test, as shown in Figure 6.

In Figure 6, the black scatter curve and the colour curves are separated and used to represent SSRT result and the 


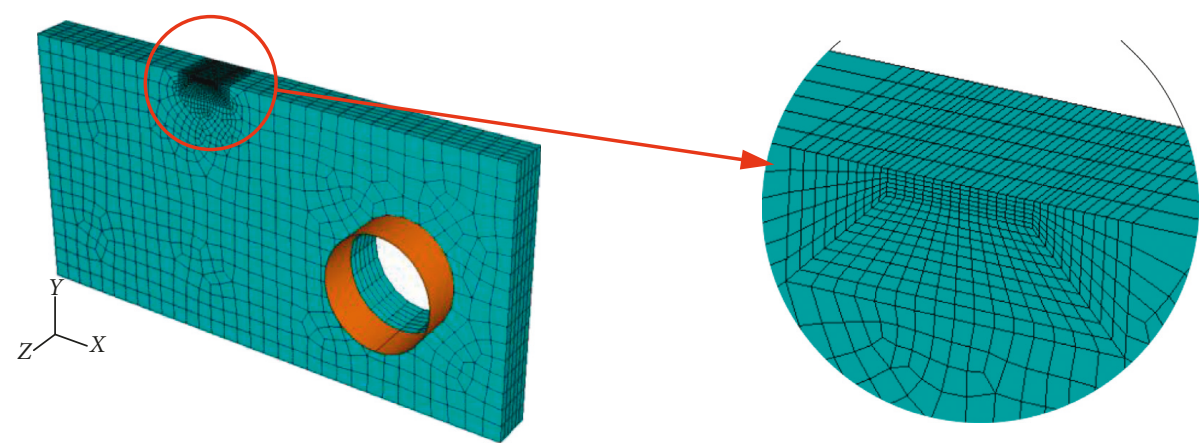

Figure 3: Mesh model: (a) global mesh; (b) mesh refinement on crack tip.

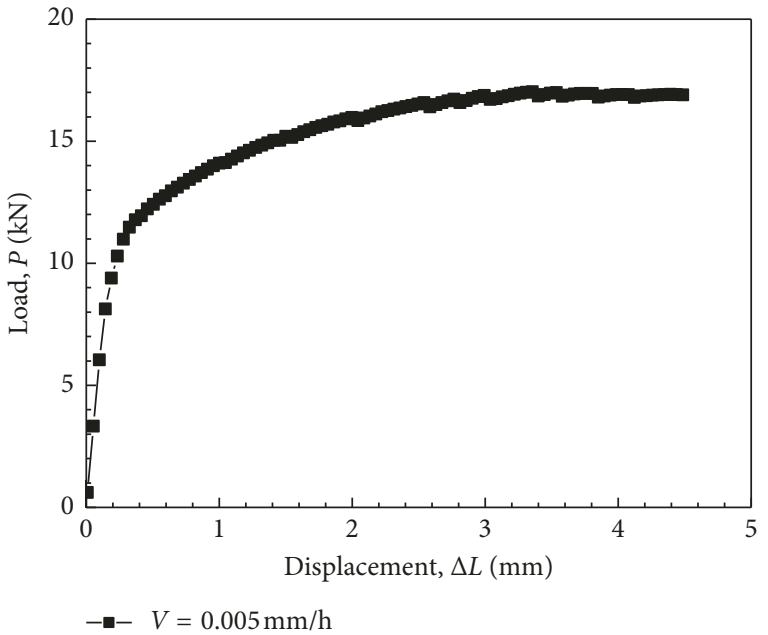

Figure 4: The relationship between tensile load and load line displacement.
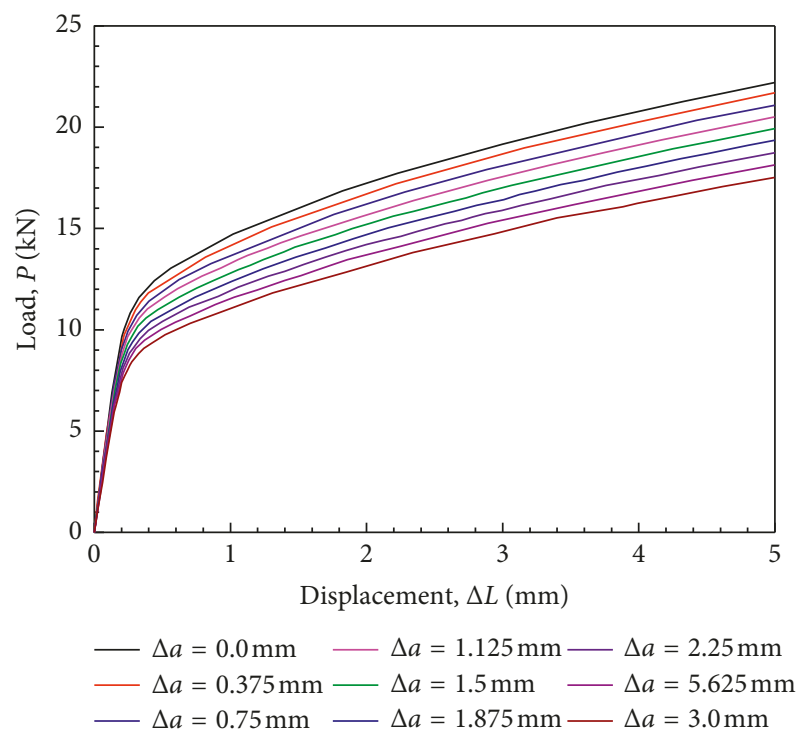

Figure 5: The relationship between tensile load and load line displacement.

numerical simulation results. The green lines are used to represent the intersection of numerical simulations and test results. By extracting the intersection of these curves, we can

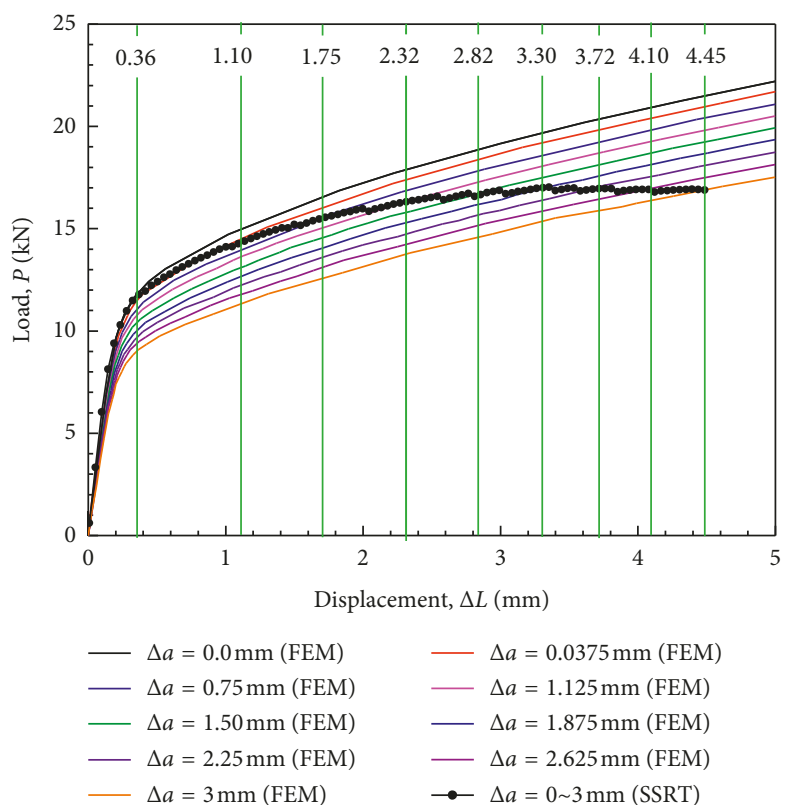

FIGURE 6: The integration of the numerical simulation and SSRT.

get the relationship between the crack propagation length $\Delta a$ and the load line displacement $\Delta L$, as shown in Figure 7.

From the relation of the crack growth length $\Delta a$ and the load-line displacement $\Delta L$, we could estimate the crack growth rate $d a / d t$ by the load-line displacement change rate $V$ and the relation of the crack growth length $\Delta a$ with the load-line displacement $\Delta L$ during the test process, which is very useful for SCC experiments on the new environmental, material, and mechanical conditions. The SSRT time, $\Delta a$, and $\Delta L$ data are shown in Table 3.

The relationship between the crack growth rate and the crack growth length is shown in Figure 8.

The stress intensity factor $K_{\mathrm{I}}$ and $J$-integral $J$ along the thickness of specimen could be worked out by using the ABAQUS software, as shown in Figures 9 and 10, which indicate that the $K_{\mathrm{I}}$ and $J$ in the centre area of the specimen are bigger than two sides. At the same time, the difference of $J$ between centre areas with two sides is bigger than $K_{\mathrm{I}}$, which indicates that the crack growth will be more rapid in the central area than on the two sides.

The change laws of the stress intensity factor $K_{\mathrm{I}}$ and $J$ integral $J$ with the crack growing in the centre area (plane 


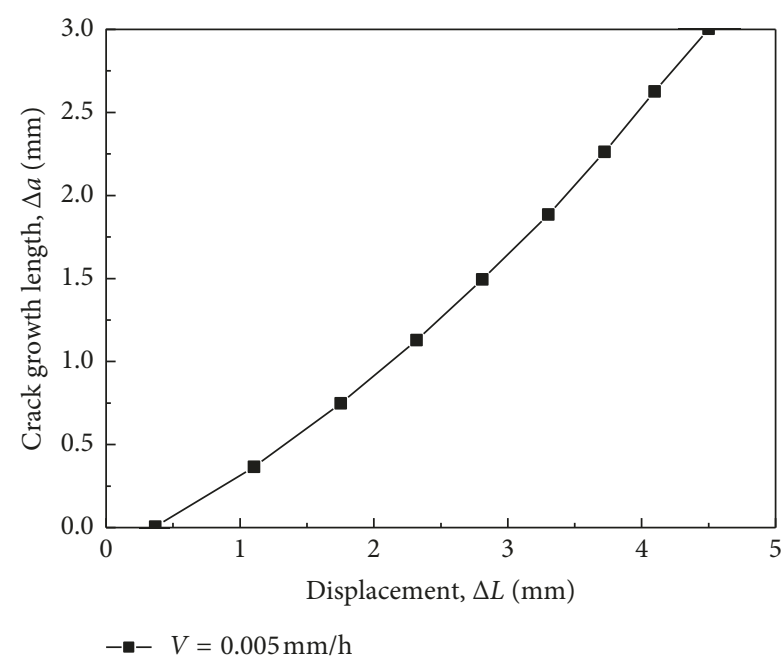

FIGURE 7: The relationship between crack growth length and loadline displacement.

TABLE 3: The SSRT experimental time, $\Delta a$, and $\Delta L$ data.

\begin{tabular}{lccc}
\hline$\Delta L(\mathrm{~mm})$ & $\Delta a(\mathrm{~mm})$ & $T(\mathrm{~h})$ & $d a / d t(\mathrm{~mm} / \mathrm{s})$ \\
\hline 0.36 & 0 & 72 & - \\
1.1 & 0.375 & 220 & $4.735 E-07$ \\
1.75 & 0.75 & 350 & $5.952 E-07$ \\
2.32 & 1.125 & 464 & $6.735 E-07$ \\
2.82 & 1.5 & 564 & $7.388 E-07$ \\
3.3 & 1.875 & 660 & $7.8918 E-07$ \\
3.72 & 2.25 & 744 & $8.400 E-07$ \\
4.1 & 2.625 & 820 & $8.892 E-07$ \\
4.485 & 3 & 897 & $9.290 E-07$ \\
\hline
\end{tabular}

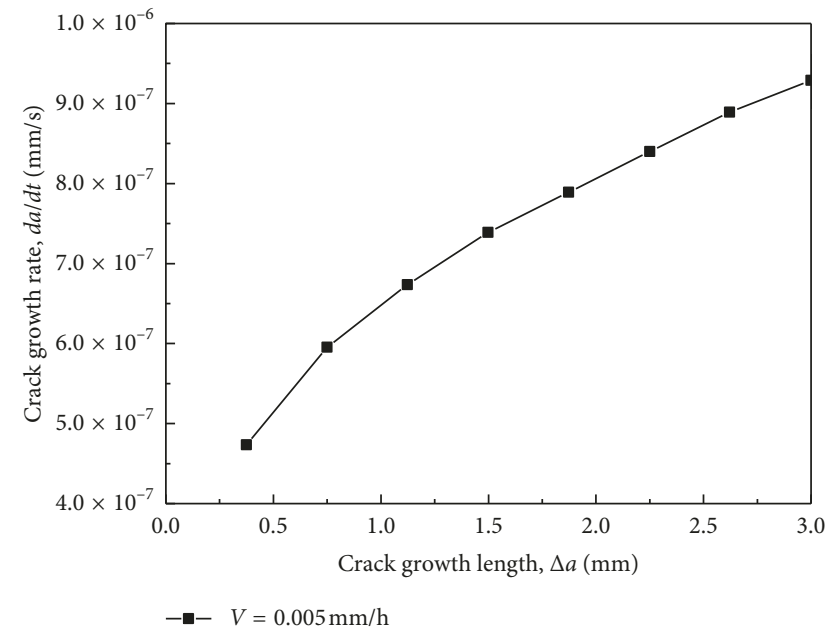

FIgURE 8: The relationship between crack growth rate and crack growth length.

strain condition) are shown in Figures 11 and 12, which indicate that both $K_{\mathrm{I}}$ and $J$ will increase as the crack propagation because of both load and crack length increasing during the test process.

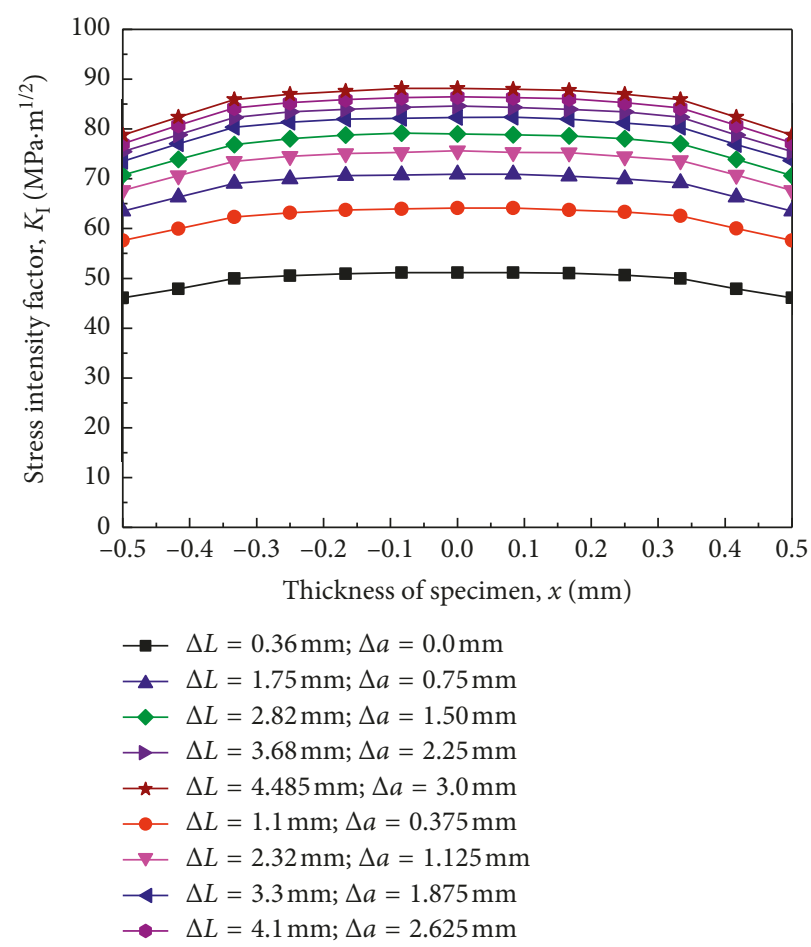

FIgUre 9: The stress intensity factor $K_{\mathrm{I}}$ along the thickness of specimen.

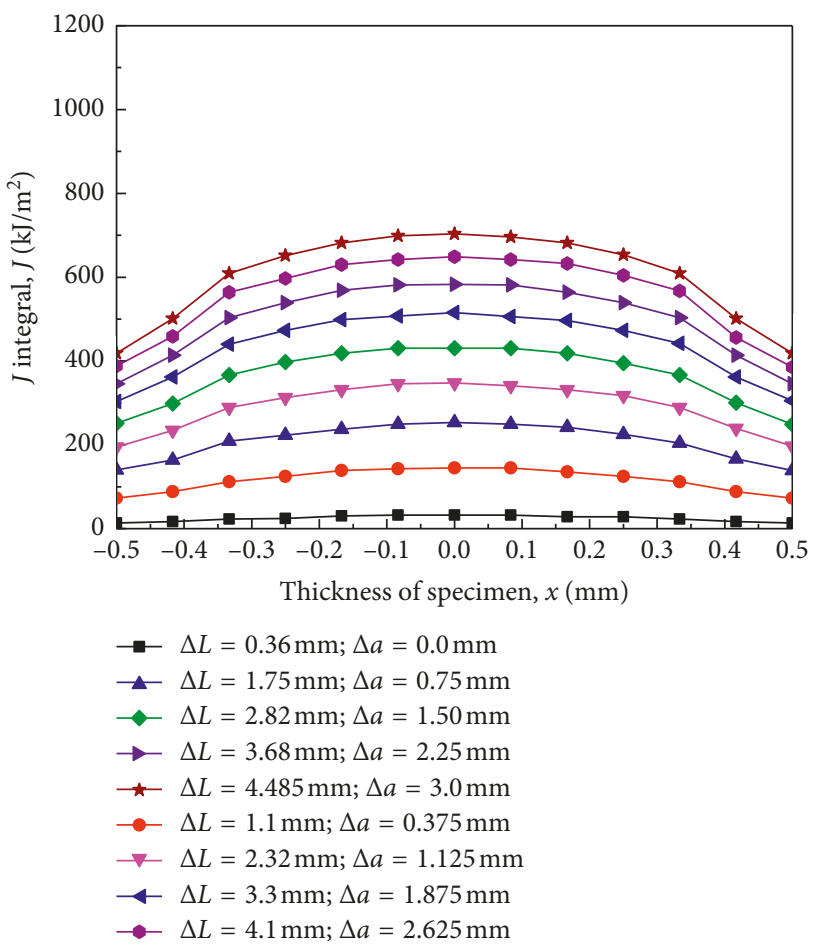

Figure 10: The $J$-integral along the thickness of specimen.

Finally, the relational curve of the SCC growth rate $d a / d t$ with stress intensity factor $K_{\mathrm{I}}$ and the relational curve of the SCC growth rate $d a / d t$ with $J$-integral $J$ could be obtained during the whole test process, which provide a clear 


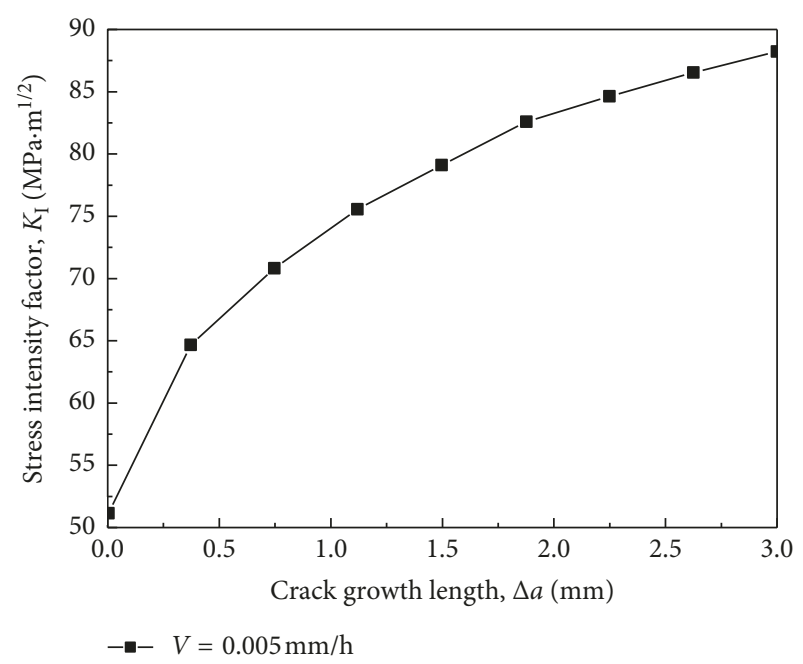

FIGURE 11: The relationship between crack growth length and stress intensity factor.

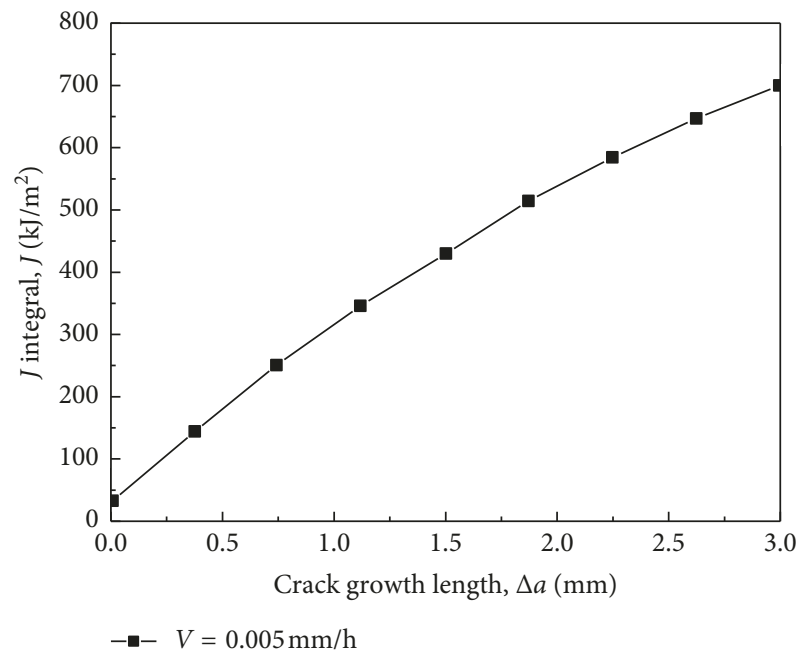

FIGURE 12: The relationship between crack growth length and $J$-integral.

understanding about the effect of the mechanical factors on SCC crack growth. It is also very convenient to analyze the effect of environmental and material factors on SCC crack growth rate and removing the mechanical factors. The relationship between $K_{\mathrm{I}}, J$, and crack growth rate is shown in Figures 13 and 14, respectively.

\section{Conclusions}

(1) A quantitatively estimated approach of SCC growing rate in the slow strain rate test based on EPFEM is proposed, which can be used to estimate the actual crack growth rate during the SSRT test.

(2) During the crack propagation process, the $K_{\mathrm{I}}$ and $J$ in the centre area of the specimen are bigger than those on the two sides. At the same time, the difference of $J$ between centre areas with two sides is bigger than $K_{\mathrm{I}}$,

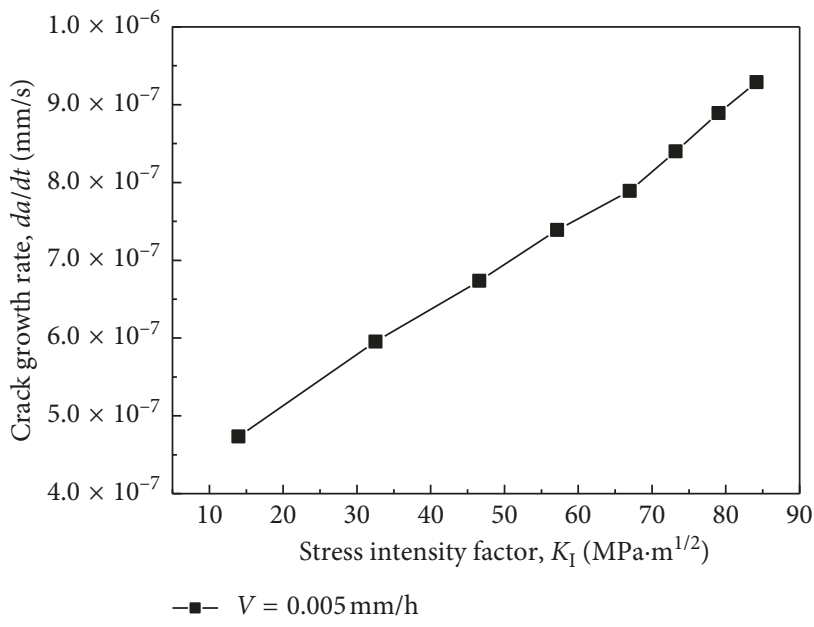

FIGURE 13: The relationship between stress intensity factor and crack growth rate.

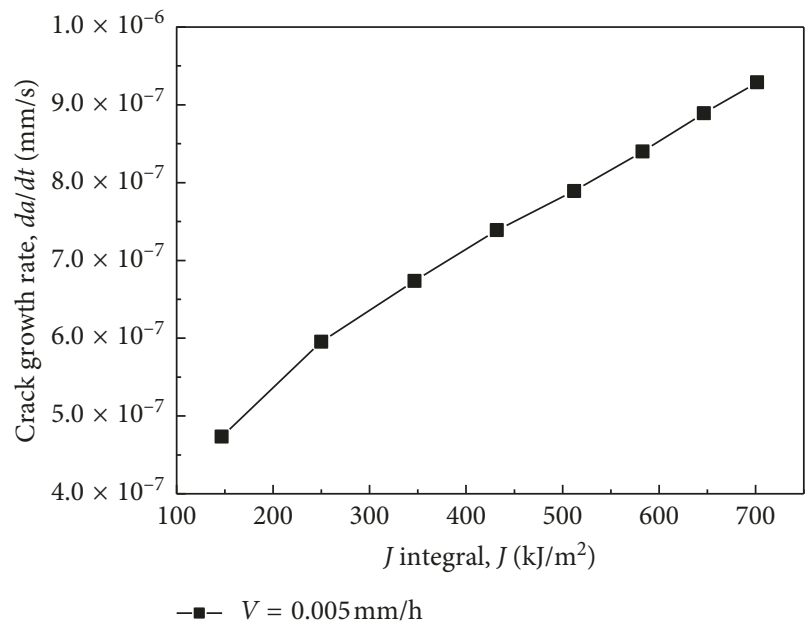

FIgURE 14: The relationship between $J$-integral and crack growth rate.

which indicates that the crack growth will be more rapid in the central area than on the two sides.

(3) When the crack propagation length is less than $3 \mathrm{~mm}$, the $K_{\mathrm{I}}$ and $J$ at the crack tip position gradually increase as the crack propagation length increases, and the increasing of $J$ is much quicker than the increasing of $K_{\mathrm{I}}$, which provides a clear understanding of the effect of the mechanical factors on EAC crack growth.

\section{Data Availability}

Previously reported Alloy 600 material chemical composition, cited as [18] within the text, and mechanical data, cited as [21] within the text, were used to support this study and are available at https://doi.org/10.1016/j.corsci.2015.05.026 and https://doi.org/10.1115/pvp2011-57317, respectively. The SSRT experiment data and the numerical simulation data of the SSRT experiment used to support the findings of this study are included in the article. 


\section{Conflicts of Interest}

The authors declare that there are no conflicts of interest regarding the publication of this paper.

\section{Acknowledgments}

This work was financially supported by the International Exchanges Programme Scheme project by the National Natural Science Foundation of China and the Royal Society (51811530311), the Natural Science Foundation of China (51475362), the Natural Science Foundation of Shaanxi Province (2018JQ5193), and the China Scholarship Council (201808610225).

\section{References}

[1] G. O. Ilevbare, F. Cattant, and N. K. Peat, "SCC of stainless steels under PWR primary circuit service conditions," in Proceedings of the EPRI MRP Conference and Exhibit Show-Materials Reliability in PWR Nuclear Power Plants, Colorado Springs, CO, USA, July 2010.

[2] T. Terachi, T. Yamada, T. Miyamoto et al., "SCC growth behaviors of austenitic stainless steels in simulated PWR primary water," Journal of Nuclear Materials, vol. 426, no. 1-3, pp. 59-70, 2012.

[3] T. Liu, S. Xia, Q. Bai et al., "Three-dimensional study of grain boundary engineering effects on intergranular stress corrosion cracking of 316 stainless steel in high temperature water," Journal of Nuclear Materials, vol. 498, pp. 290-299, 2018.

[4] D. Du, K. Chen, H. Lu et al., "Effects of chloride and oxygen on stress corrosion cracking of cold worked 316/316L austenitic stainless steel in high temperature water," Corrosion Science, vol. 110, pp. 134-142, 2016.

[5] H. Xue, Y. Cui, G. Li et al., "Crack growth driving force at tip of stress corrosion cracking in nuclear structural materials at initial stage," Rare Metal Materials and Engineering, vol. 47, no. 8, pp. 2365-2370, 2018.

[6] L. Dong, Q. Peng, E.-H. Han, W. Ke, and L. Wang, "Stress corrosion cracking in the heat affected zone of a stainless steel 308L-316L weld joint in primary water," Corrosion science, vol. 107, pp. 172-181, 2016.

[7] Q. J. Peng, J. Kwon, and T. Shoji, “Development of a fundamental crack tip strain rate equation and its application to quantitative prediction of stress corrosion cracking of stainless steels in high temperature oxygenated water," Journal of Nuclear Materials, vol. 324, no. 1, pp. 52-61, 2004.

[8] W. Hwang, S. Bae, J. Kim, S. Kang, N. Kwag, and B. Lee, "Acoustic emission characteristics of stress corrosion cracks in a type 304 stainless steel tube," Nuclear Engineering and Technology, vol. 47, no. 4, pp. 454-460, 2015.

[9] J. Kovac, C. Alaux, T. J. Marrow, E. Govekar, and A. Legat, "Correlations of electrochemical noise, acoustic emission and complementary monitoring techniques during intergranular stress-corrosion cracking of austenitic stainless steel," Corrosion Science, vol. 52, no. 6, pp. 2015-2025, 2010.

[10] T. Satoh, T. Nakazato, S. Moriya, S. Suzuki, and T. Shoji, "Quantitative prediction of environmentally assisted cracking based on a theoretical model and computer simulation," Journal of Nuclear Materials, vol. 258-263, pp. 2054-2058, 1998.

[11] J. Shi, J. Wang, and D. D. Macdonald, "Prediction of primary water stress corrosion crack growth rates in Alloy 600 using artificial neural networks," Corrosion Science, vol. 92, pp. 217-227, 2015.

[12] R. O. Ritchie and K. J. Bathe, "On the calibration of the electrical potential technique for monitoring crack growth using finite element methods," International Journal of Fracture, vol. 15, no. 1, pp. 47-55, 1979.

[13] L. Zhang and J. Wang, "Effect of dissolved oxygen content on stress corrosion cracking of a cold worked 316L stainless steel in simulated pressurized water reactor primary water environment," Journal of Nuclear Materials, vol. 446, no. 1-3, pp. 15-26, 2014.

[14] Z. Zhai, M. B. Toloczko, M. J. Olszta, and S. M. Bruemmer, "Stress corrosion crack initiation of alloy 600 in PWR primary water," Corrosion Science, vol. 123, pp. 76-87, 2017.

[15] Z. Bruemmer, X. Wu, and J. Tan, "In-situ monitoring of stress corrosion cracking of 304 stainless steel in high-temperature water by analyzing acoustic emission waveform," Corrosion Science, vol. 146, pp. 90-98, 2019.

[16] X. Zhong, S. C. Bali, and T. Shoji, "Accelerated test for evaluation of intergranular stress corrosion cracking initiation characteristics of non-sensitized 316 austenitic stainless steel in simulated pressure water reactor environment," Corrosion Science, vol. 115, pp. 106-117, 2017.

[17] C. Ma, J. Mei, Q. Peng, P. Deng, E.-H. Han, and W. Ke, "Microstructure characterization of the fusion zone of an alloy 600-82 weld joint," Journal of Materials Science \& Technology, vol. 31, no. 10, pp. 1011-1017, 2015.

[18] Y. Han, J. Mei, Q. Peng, E.-H. Han, and W. Ke, "Effect of electropolishing on corrosion of Alloy 600 in high temperature water," Corrosion Science, vol. 98, pp. 72-80, 2015.

[19] Standard, E399-90, 1990 Annual Book of ASTM Standards, pp. 13-15, ASTM, 2002.

[20] H. Xue, K. Ogawa, and T. Shoji, "Effect of welded mechanical heterogeneity on local stress and strain ahead of stationary and growing crack tips," Nuclear Engineering and Design, vol. 239, no. 4, pp. 628-640, 2009.

[21] H. Xue, X. Gong, L. Zhao et al., "Effect of mechanical parameter selection in quantitative estimation of the growth of environmentally assisted cracks at flaws in light water reactor components with complex mechanical condition," in Proceedings of the ASME 2011 Pressure Vessels and Piping Conference, pp. 893-899, American Society of Mechanical Engineers, Baltimore, MD, USA, July 2011.

[22] ABAQUS/Standard User's Manual Version 6.14, Dassault Systèmes Simulia Corp., Providence, RI, USA, 2014. 


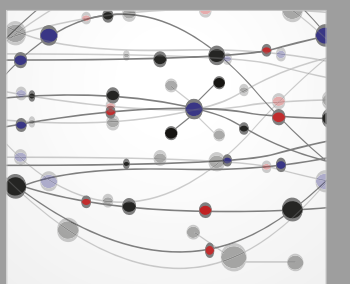

The Scientific World Journal
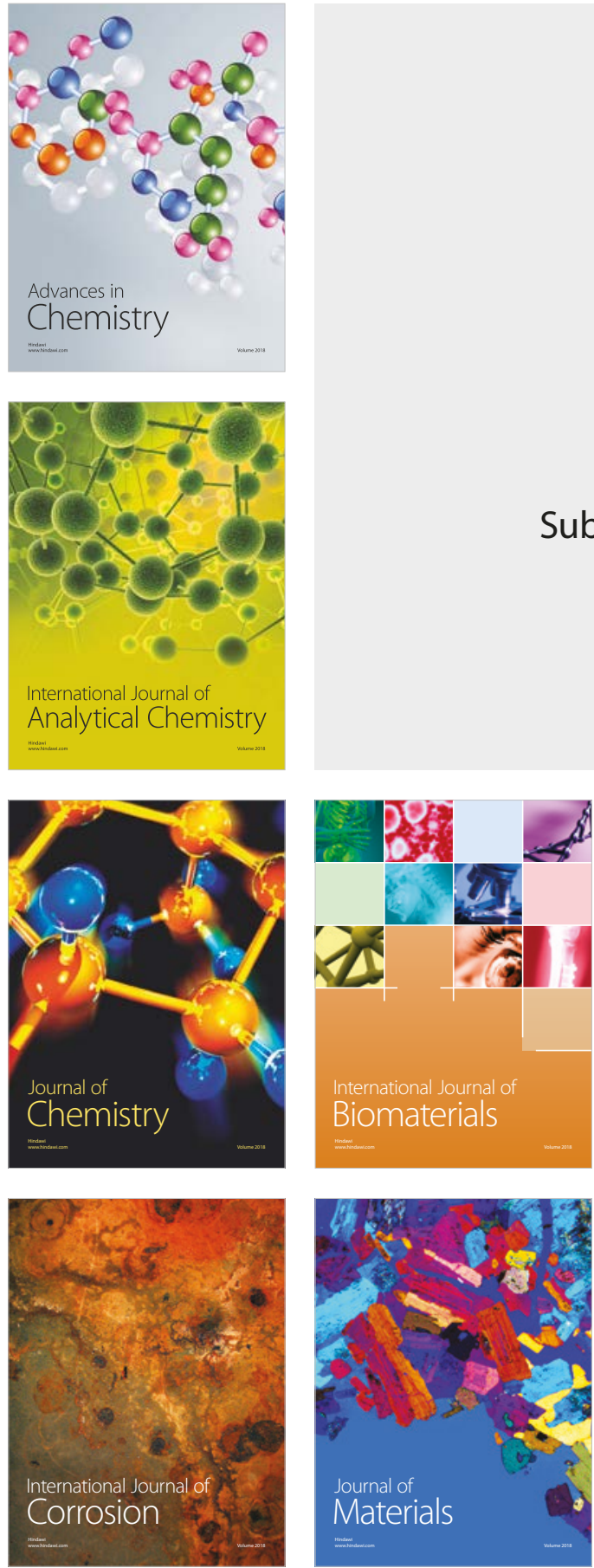

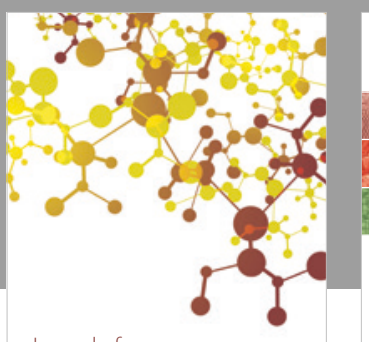

Journal of

Applied Chemistry
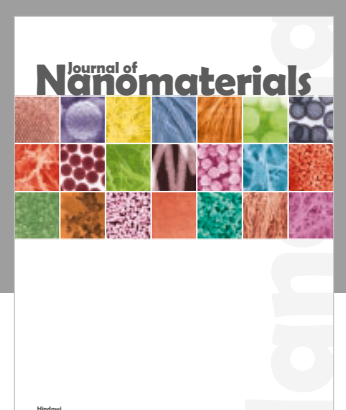

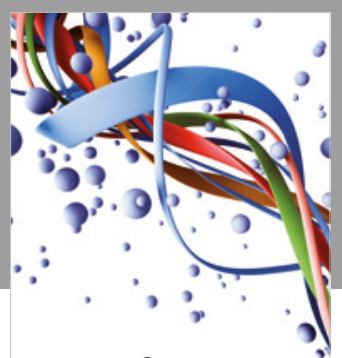

Scientifica

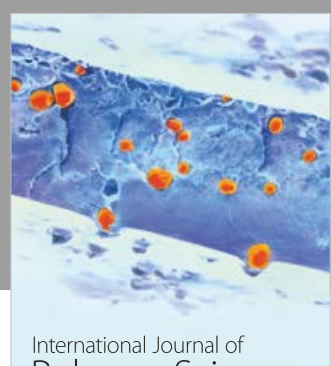

Polymer Science

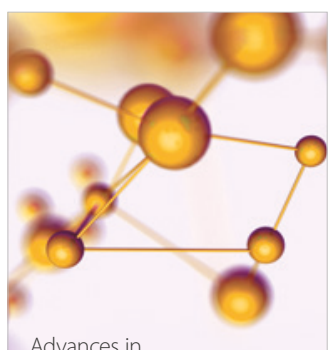

Physical Chemistry
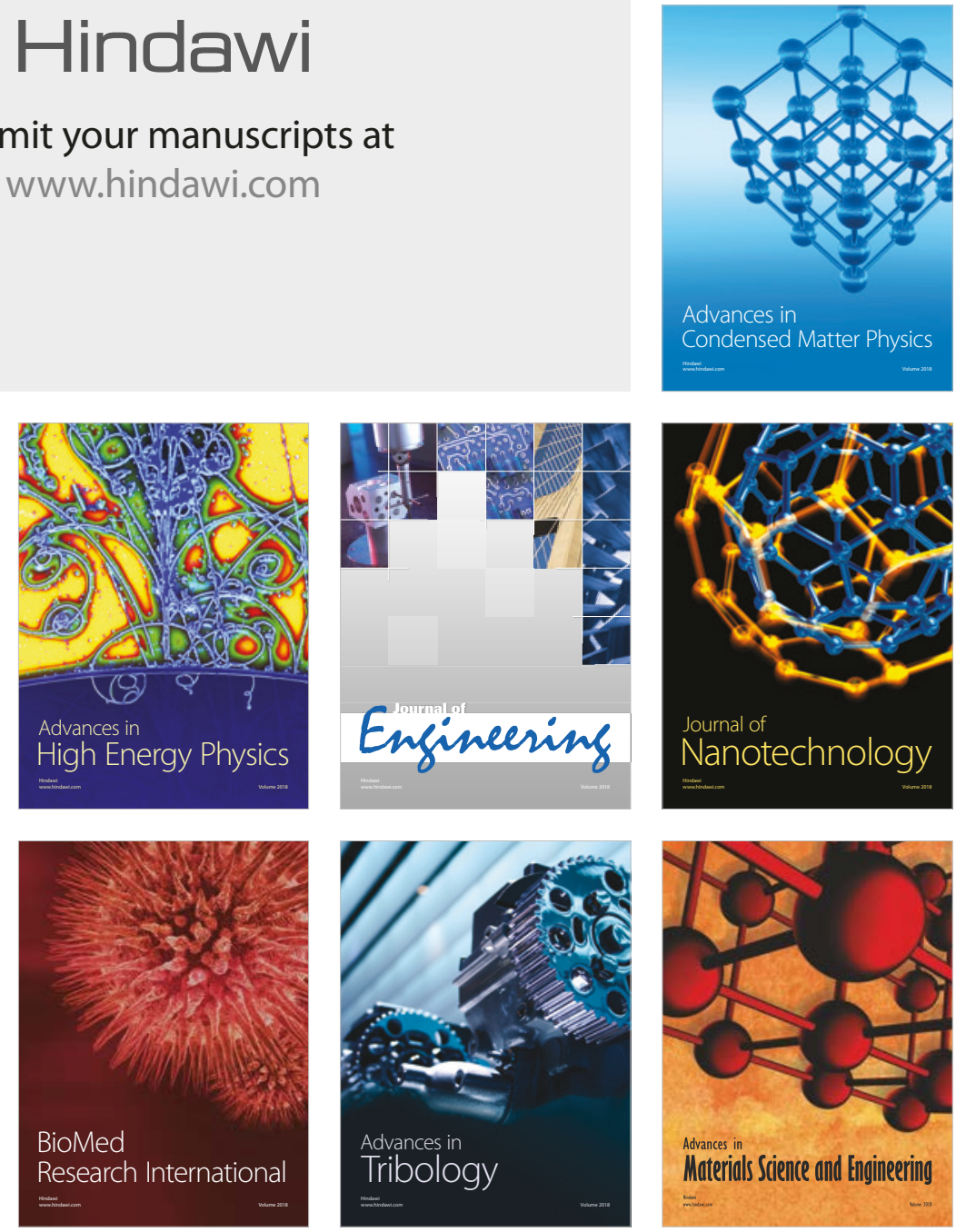